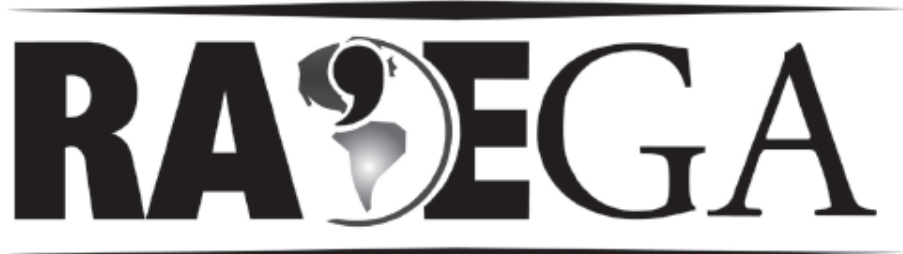

O ESPAÇO GEOGRÁFICO EM ANÁLISE

\title{
OS ELEMENTOS DO ESPAÇO TURÍSTICO DA FRONTEIRA BRASIL-BOLÍVIA
}

\section{THE TOURISTIC SPACE ELEMENTS AT BRAZIL-BOLIVIA BORDER}

\author{
NILZE DE PAULA FIGUEIREDO ${ }^{1}$ \\ EDGAR APARECIDO DA COSTA ${ }^{2}$ \\ BEATRIZ LIMA DE PAULA ${ }^{3}$
}

\section{Resumo}

O espaço geográfico objeto deste estudo foi a fronteira Brasil-Bolívia, envolvendo as áreas urbanas dos municípios brasileiros de Corumbá e Ladário e das secciones municipales bolivianas de Puerto Quijarro e Puerto Suárez. O objetivo deste estudo foi analisar os elementos do espaço turístico fronteiriço, especulando sobre suas aproximações ou divergências com vistas a um planejamento integrado. Foram utilizados na metodologia de trabalho, dados secundários e resultantes do trabalho de campo. Essa fronteira produz um emaranhado de relações, de fluxos. Os elementos espaciais presentes imbricam complexas racionalidades ora aproximando, ora afastando e outras vezes desconsiderando as possibilidades que a fronteira pode traduzir.

Palavras-chave: Fronteira; espaço; turismo.

\footnotetext{
1 Turismóloga, mestre em Estudos Fronteiriços, UFMS, nilzepaula@hotmail.com

${ }^{2}$ Geógrafo, professor adjunto do curso de Geografia e do Programa de Mestrado em Estudos Fronteiriços da Universidade Federal de Mato Grosso do Sul - UFMS, campus do Pantanal, edgarac10@gmail.com

3 Engenheira cartógrafa, professora assistente do curso de Geografia da Universidade Federal do Amapá - UNIFAP, doutoranda em Geociências e Meio Ambiente - UNESP/ Rio Claro-SP, beatriz unesp@yahoo.com
} 


\section{Abstract}

The geographical space aimed by this study was the Brazil-Bolivia border, involving the urban areas of the Brazilian city, Corumbá, and the Bolivian ones, Puerto Quijarro and Puerto Suárez. The objective of this study was to analyze the touristic border spaces, speculating about their similarities and divergences regarding integrated planning. Secondary data, resulting from field work, was used in the methodology. The border generates a tangled web of relationships and streams. The presented spatial elements mix complex rationalities, sometimes approaching, sometimes denying and even disregarding the possibilities that can be translated by the border.

Key Words: Border; space; tourism.

\section{Introdução}

A linha de limite internacional entre Brasil e Bolívia possui uma extensão total de $3.423 \mathrm{~km}$, perfazendo cerca de $20 \%$ da divisa territorial brasileira com os países vizinhos. A faixa de fronteira envolve quatro estados brasileiros (Mato Grosso do Sul, Mato Grosso, Rondônia e Acre) e três departamentos bolivianos (Santa Cruz de la Sierra, Beni e Pando). Este artigo teve como universo de estudo as áreas urbanas fronteiriças localizadas no Pantanal Sul, formadas por Corumbá e Ladário (Mato Grosso do Sul, Brasil) e Arroyo Concepcion, Puerto Quijarro e Puerto Suárez (Santa Cruz de la Sierra, Bolívia) (Figura 1).

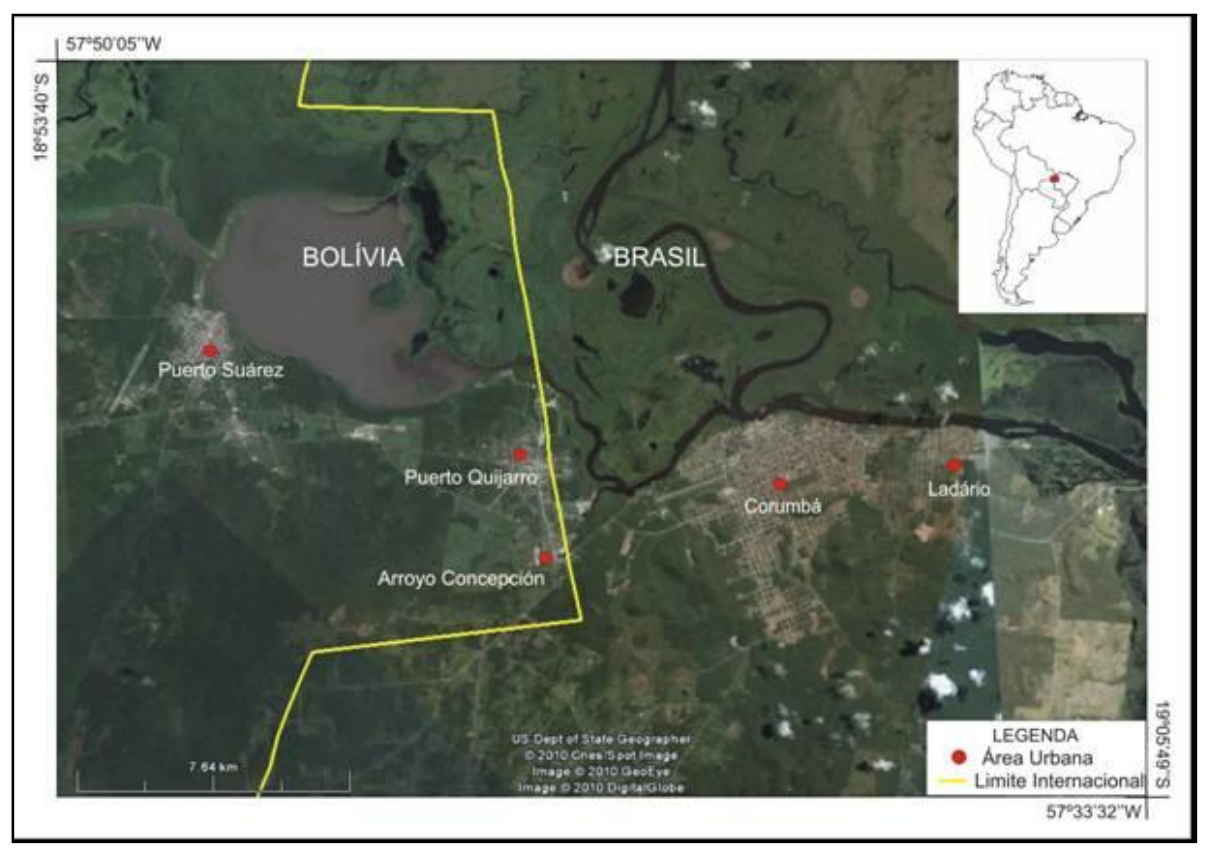

Figura 1 - A fronteira Brasil-Bolívia: malha urbana no Pantanal Sul, 2010. Autor: PAULA, B.L., 2010. 
É oportuno dizer que o espaço fronteiriço abordado neste estudo foi construído em tempos diferentes. Os municípios brasileiros começaram a receber os primeiros habitantes brancos ainda no século XVIII, sendo que inicialmente Corumbá e Ladário formavam uma única unidade. Enquanto o primeiro é um dos mais antigos do Estado, apenas na década de 1950 é que Ladário tornou-se município. Do lado boliviano, Puerto Quijarro é mais recente, sendo iniciada sua ocupação na segunda metade do século XX e transformado em município somente em 1991. Arroyo Concepción é um districto de Puerto Quijarro (portanto, será tratado no âmbito deste) que teve sua formação iniciada nos anos 1970 (OLIVEIRA, 1998). Puerto Suarez teve povoamento mais antigo, sendo constituído cerca de um século depois de Corumbá e Ladário. Entretanto, a formação dessa fronteira é relativamente recente e, conforme Oliveira (1998) começou a ser conformada a partir de meados da década de 1970.

Vale lembrar que as estruturas hierárquicas de governo são diferentes. Corumbá e Ladário são municípios pertencentes ao Estado do Mato Grosso do Sul, ligado diretamente ao poder central da República Federativa do Brasil. Puerto Suarez e Puerto Quijarro são respectivamente a Primera e Tercera Sección Municipal da Província de German Busch, pertencente ao Departamento de Santa Cruz de La Sierra que, por sua vez, está articulado com o governo central da República da Bolívia.

Em acordo com Silva (2009, p.30),

[...] enquanto o Brasil se configura com uma união de estados, a Bolívia é um estado unitário descentralizado executivamente, e atualmente passa por um processo de mudança ou adequação às determinações da Nueva Consituición Política del Estado, aprovada no ano de 2008. Essas especificidades entre os países refletem não apenas nas configurações dos poderes, mas atuam também de forma direta na implantação de políticas públicas [...]

Logo, esse espaço fronteiriço apresenta duas formas distintas de condução política, separada pelo limite internacional e, ao mesmo tempo, una pela convivência entre os povos. O objetivo deste estudo foi descrever os 
elementos do espaço turístico fronteiriço, especulando sobre suas aproximações ou divergências com vistas a um planejamento integrado. Tratou-se de um olhar para o espaço fronteiriço a partir da indicação metodológica sugerida por Milton Santos, demonstrando suas possibilidades para os estudos aplicados a uma geografia do turismo.

\section{Procedimentos}

Os elementos do espaço foram tratados em conformidade com a proposição de Milton Santos, em "Espaço e método", (SANTOS, 2008 ${ }^{4}$ ) que propõe cinco itens: os homens, as firmas, as instituições, o meio ecológico e as infraestruturas. No escopo da pesquisa descritiva, foi realizado um arrolamento de dados secundários obtidos do Instituto Brasileiro de Geografia e Estatística (IBGE), do Instituto Nacional de Estadística (INE) e das prefeituras municipais. Também foi utilizada entrevista semi-estruturada e conversas informais com os gestores de turismo locais e representantes das agências e empresas de turismo dessas localidades. Outro mecanismo de abordagem foram as conversas informais com alguns turistas sobre a qualidade dos serviços turísticos oferecidos. Os resultados obtidos a partir deste instrumental foram organizados numa perspectiva qualitativa, para a leitura e arranjo da produção do turismo nesse espaço fronteiriço. O trabalho de campo ocorreu entre fevereiro de 2009 e janeiro de 2010. Do ponto de vista da ética, a pesquisa foi submetida e aprovada pelo Comitê de Ética da Universidade Federal de Mato Grosso do Sul (UFMS).

Segundo Santos (2008), os elementos do espaço são, e possuem funções muitas vezes, intercambiáveis e redutíveis uns aos outros. Por isso, a noção de espaço obrigatoriamente é dada pela totalidade e não pelas particularidades. Esses elementos devem ser considerados como variáveis já que estão submetidos a variações quantitativas e qualitativas, mudando, seu papel e sua posição no sistema temporal e no sistema espacial a cada momento histórico e, portanto o valor que lhe é atribuído no referido contexto.

\footnotetext{
${ }^{4}$ A primeira edição é de 1985. O livro é composto por vários ensaios escrito nos anos 1980.
} 
Esses elementos são sempre os mesmos, mas que em cada lugar assumem conformação particular. Em todo momento esses componentes têm, para si, disponibilidade diversa de tecnologia cuja combinação com capital e trabalho permite uma valoração também diversa de cada um. Esse valor é resultante do papel da variável para o conjunto espacial.

As técnicas também são variáveis em conformidade com o tempo. Milton Santos (2008) indica que os elementos do espaço são componentes de um sistema que é o próprio espaço, motivados por suas relações e comandados pelo modo de produção dominante. Logo, o estudo possui relevância para retratar esse período inicial do século XXI. Como todo sistema pode ser dividido em subsistemas, se procurou demonstrar cada um dos componentes da produção do espaço turístico fronteiriço, tendo como visão analítica a totalidade e não das partes, apesar de consideradas. Por isso, em conformidade com Santos (2008), não foi possível tratar um elemento isoladamente, e sim, em sua aproximação com outro ou outros.

\section{Os homens}

De acordo com Santos (2008), os homens são elementos do espaço na qualidade de candidatos ou de fornecedores de trabalho. No caso deste estudo, optou-se por manter a denominação original, apesar da preferência por algo mais genérico como, por exemplo, seres humanos em condição de trabalho. São aqueles ligados diretamente ao trade turístico (os guias, os garçons, as camareiras, os taxistas, dentre outros), mais a reserva de mão-deobra disponível. Os turistas presentes nesse espaço, pelo fato de demandarem "[...] um certo tipo de trabalho para outros [...]" (SANTOS, 2008, p.16), também podem ser incluídos, muito embora não sejam componentes diretos desse "exército de reserva de trabalhadores". Infelizmente não se pode traçar um perfil fidedigno dos turistas que chegam a Corumbá - fato confirmado por Santos Júnior (2010) ao indicar que a Ficha Municipal de Registro de Hóspedes (FMRH), invariavelmente, possui preenchimento inadequado para tal caracterização. Sendo assim, a abordagem desses foi preterida pela dos 
envolvidos diretamente/mais permanentemente (ou pelo menos com uma pausa maior de permanência) nesse espaço fronteiriço.

Apenas o município de Corumbá conta com guias especializados no serviço. Foram encontrados aproximadamente 10 guias de turismo com o curso técnico e cadastrados pela Empresa Brasileira de Turismo (EMBRATUR). Porém, somente três guias atuavam no mercado de trabalho, em Corumbá durante a pesquisa de campo.

Uma tentativa de capacitação para melhorar o atendimento aos turistas foi a realização de um curso para formação de guias mirins, estimulado pela Prefeitura Municipal de Corumbá e patrocinado pela empresa Vale que teve início em julho de 2008 com duração de 06 meses, tendo 37 alunos inscritos, mas somente 26 chegaram a se formar. A explicação para essa baixa foi a mudança de cidade e o ingresso nas Forças Armadas. Para a formação dos guias foram selecionados alunos a partir dos 16 anos de idade que estudavam em escolas públicas e com bom aproveitamento escolar. O projeto teve a finalidade de proporcionar a oportunidade do primeiro emprego, almejando futuramente a inserção no mercado de trabalho no setor turístico. Alguns resultados foram observados, como a atuação dos guias em determinados eventos no município, como por exemplo, no Festival América do Sul e fazendo receptivo na inauguração do Centro de Convenções (em 2009). Contudo, a atuação ocorre de forma esporádica, quando são convocados pela Fundação de Cultura e Turismo.

Em relação aos funcionários do ramo de alimentação (garçons) constatou-se que não possuem capacitação para o atendimento aos clientes e a qualificação desses trabalhadores está baseada na experiência adquirida com o próprio trabalho. Muitas vezes recebem orientação dos próprios empresários que se acreditam experientes no ramo. Em Corumbá estão organizados na forma de sindicato, porém sem grandes expressões/força políticas. Ladário e os municípios bolivianos não apresentam essa forma de organização de classe. 
Situação semelhante acontece com os funcionários do ramo de hospedagem que não são capacitados, mas que são considerados aptos, pelos donos dos estabelecimentos, a executar as atividades inerentes ao setor de recepção e governança. No que se refere à forma de organização, a classe não possui nenhum tipo particular de representação.

Contudo, empiricamente se percebeu que tal entendimento dos proprietários não é verdadeiro. Através da observação do atendimento no balcão e de conversas informais com alguns turistas e hóspedes nos principais hotéis da fronteira se teve a confirmação da fragilidade desse tipo de serviço prestado nessas cidades. Os trabalhadores não estão preparados para lidar com clientes mais exigentes de atenção e invariavelmente deixam o mesmo sem explicação do que está sendo providenciado em relação à sua solicitação. Para o turista global não basta a solução de seu pedido, mas também a informação dos procedimentos que estão sendo adotados. Não foi essa a postura verificada nos balcões de atendimento nesses hotéis, coroando com a principal reclamação dos turistas entrevistados.

No setor de transporte urbano destacam-se os taxistas e os mototaxistas, no lado brasileiro e apenas os primeiros no lado boliviano ${ }^{5}$. No Brasil, os taxistas são representados por um sindicato profissional tanto em Corumbá, quanto em Ladário. O mesmo se observa do lado boliviano. Contudo, não existe uma política de integração territorial fronteiriça para a circulação desses veículos, dificultada pelas diferenças de custos entre os países, já que na Bolívia o preço do combustível é menos da metade dos preços praticados no lado brasileiro. Outro aspecto é a forma como o serviço é cobrado. Ainda não existe uma regulamentação e o uso dos taxímetros não é uma praxe cotidiana. Muitas vezes os valores da corrida são acertados antecipadamente sem um critério de uso comum. Vale registrar que a frota de táxi boliviana é muito antiga e funciona no "sistema lotação", ou seja, não é exclusivista a um passageiro, podendo receber outros durante o percurso.

\footnotetext{
${ }^{5}$ Os taxistas, dada sua forma de organização, também são tratados como empresas ligadas ao transporte de atendimento aos turistas.
} 
Os mototaxistas foram reconhecidos como profissão muito recentemente no Brasil (final de 2008). Na Bolívia não é reconhecido, tampouco praticado, talvez por conta dos baixos custos e preços cobrados pelo serviço de táxi. As prefeituras de Corumbá e Ladário têm um sistema de cadastramento para liberação de alvarás, mas ainda assim, existe uma grande quantidade de informais que prestam esse tipo de serviço nessas cidades, cujo quantitativo não é conhecido.

Em Corumbá foi constatado que a tripulação e os piloteiros de alguns dos barcos hotéis receberam ou recebem capacitação constante para atendimento aos turistas. Quanto ao atendimento específico de estrangeiros, não se verificou a existência de guias que falassem fluentemente o inglês ou espanhol. Contudo, na maioria das vezes esses turistas falam o espanhol que é de fácil entendimento para os piloteiros e tripulação devido à proximidade com a Bolívia. Também, dependendo do grupo, eles já trazem um guia que os acompanha e fala com fluência o espanhol e/ou inglês. Na falta desse a tripulação acaba se entendendo através de mímicas ou até mesmo se arrisca a falar um pouco de espanhol, numa versão conhecida regionalmente como "portunhol". Tanto os piloteiros como a tripulação estão organizados em forma de sindicato que foi criado em 1981 com a finalidade de representar legalmente a categoria dos aquaviários. Este sindicato não representa somente os piloteiros, mas toda a categoria do sistema aquaviário, incluindo a tripulação dos barcos-hotel, da embarcação do sistema de dragagens, enfim, de toda embarcação que se utiliza do sistema portuário de Corumbá e Ladário. A finalidade do sindicato é representar tanto administrativa quanto judicialmente, como também reivindicar por melhores salários. Cuida de toda a documentação para fins de aposentadoria e de outros benefícios sociais, além de ser responsável pela emissão de carteira profissional. Em Ladário não foi registrado esse tipo de organização local, sendo que a grande maioria está vinculada ao sindicato dos aquaviários de Corumbá. No lado fronteiriço boliviano não existe essa forma de aparelhamento social.

Também foram considerados como homens presentes no espaço geográfico, os candidatos a uma vaga no mercado de trabalho específico do 
trade turístico. É uma espécie de reserva de mão-de-obra, uma potencialidade existente. Considerando que não existe uma exigência empresarial de capacitação dos trabalhadores, como apontado anteriormente, essa reserva pode ser utilizada a qualquer instante.

Se for considerada como faixa etária ótima para trabalho aquela que vai de 16 a 50 anos, pelos dados do IBGE e do INE, a maioria da população desta fronteira está em condições de trabalho. A soma da população fronteiriça nesta faixa etária, considerando apenas as áreas urbanas, é da ordem de 100 mil pessoas trabalhando ou disponíveis como reserva de mão-de-obra.

Um dos elementos importantes para indicar a relativa capacitação da reserva de mão de obra é a taxa de alfabetização. Isso não significa uma população apta ao trabalho, mas predisposta a aprender, mais facilmente, as funções que Ihe serão atribuídas. De acordo com o IBGE, no ano 2000, em Ladário-MS, 92,30\% da população com 10 anos ou mais eram alfabetizadas, enquanto em Corumbá-MS esse indicador correspondeu a 91,50\%. Em conformidade com os dados do Censo Nacional de Población y Vivienda, 1992 (divulgados pelo INE), Puerto Suarez apresentava $93,11 \%$ de população alfabetizada, enquanto Puerto Quijarro detinha 94,00\%. Nota-se, aparentemente, que os indicadores dos vizinhos são melhores que os brasileiros, inclusive pelos anos mais recentes em termos de levantamento (o censo brasileiro é mais atual). Entretanto, cabe considerar que o censo boliviano considera população alfabetizada, para efeitos de cálculo, somente aquela maior de 15 anos.

Outro indicador a ser considerado é o Índice de Desenvolvimento Humano (IDH). O IDH-M considera informações sobre educação, longevidade e renda. Quanto mais perto de 1,000 melhor é a condição desse indicador. Em Ladário, o IDH-M, em 2000, foi 0,775, enquanto em Corumbá-MS esse indicador foi 0,771 . No lado boliviano as aproximações estatísticas são mais recentes para esse indicador, sendo de 0,694 em 2000, avançando para 0,719 em 2005, no caso de Puerto Suarez e; de 0,710 para 0,734, no mesmo 
período, para Puerto Quijarro. Portanto, indicadores apenas medianos para os territórios desta fronteira.

Essa força aparentemente intangível se mostra materializada, por exemplo, no esquema de cadastramento para ocupação das barracas para vendas de comidas, bebidas e artesanato nos eventos que ocorrem em Corumbá. A Prefeitura Municipal estipula um limite quantitativo para os vendedores ambulantes que são selecionados por ordem de inscrição, sem distinção de serem brasileiros ou bolivianos. É realizado um sorteio entre os inscritos e assumida a obrigação de atender as exigências da Fundação da Cultura e Turismo (denominação atual) e de qualidade dentro dos padrões da vigilância sanitária. Portanto, resumidamente se pode dizer que os homens são elementos amplamente dissimétricos nesse espaço fronteiriço.

\section{As firmas}

Milton Santos (2008) aponta que as firmas, como elemento constituinte do espaço, têm a função de produzir bens, serviços e idéias. No contexto desta pesquisa as firmas foram representadas pelas agências, hotéis, barcos-hotel, restaurantes, empresas de transporte e os artesãos que formam o chamado trade turístico.

Em Puerto Quijarro os locais de hospedagem são muitos diversos do ponto de vista do oferecimento das acomodações, abrangendo desde hotel 5 estrelas até aqueles com características bastante próximas de estruturas residenciais. Nesse sentido, Puerto Suarez conta com uma estrutura hoteleira ainda mais simples.

No lado brasileiro, a estrutura hoteleira é mais complexa, com maiores opções de acomodação tendo em Corumbá sua maior concentração. Ladário oferece poucas possibilidades hoteleiras na área urbana que é ampliada, parcialmente, pela proximidade da Codrasa (uma área formada a partir de uma espécie de polder), onde estão algumas pousadas. Corumbá possui quantidade e variedade de hotéis, sendo uns poucos de melhor padrão e a grande maioria de padrão médio e inferior. Apesar da quantidade - cerca de 
trinta hotéis - na época das grandes festividades faltam leitos para atender a demanda.

A produção do turismo, em qualquer lugar, acontece pela trama social da comunidade, dos empresários e do Estado. Dessas relações e da capacidade desigual de forças desses agentes resultam materialidades e imaterialidades que são socialmente produzidas, mas apropriadas por aqueles que desenvolvem capacidade para absorver essas oportunidades.

Para identificação das empresas que atuam no mercado turístico em Corumbá optou-se pela análise daquelas credenciadas pela Associação Corumbaense das Empresas Regionais de Turismo - ACERT, criada em 21 de outubro de 1985. Essa entidade tem como finalidade congregar todas as empresas relacionadas ao turismo, inclusive as de apoio e prestadoras de serviço, tais como: barco-hotel, agenciadores e promotores de viagem, hotéis, restaurantes, estabelecimentos de artesanato, sendo possível o ingresso dos demais similares com base territorial na área do Pantanal objetivando a promoção social e econômica, estimulando o desenvolvimento e defendendo os interesses dos associados (informação oral ${ }^{6}$ ).

De acordo com a pesquisa foi identificado que 100\% das empresas de turismo, da cidade de Corumbá, são voltadas para o atendimento do turismo de pesca e quase todas executam roteiros para compras na Bolívia (Figura 2). Desse total, 35\% atende as demandas por turismo ecológico, com passeios pela Estrada Parque e pelo rio Paraguai - nos chamados safáris fotográficos.

Das 21 empresas cadastradas, apenas três possuem escala de atuação regional e nacional - as demais operam na localidade. Por vezes os passeios oferecidos incluem pernoite em propriedades localizadas na Estrada Parque que possuem a opção de turismo rural e que servem de apoio ao turismo local. Somente três empresas disponibilizam city tour, que não ocorre como parte de um "pacote turístico", mas a partir da necessidade gerada pelos grupos de turistas que chegam a Corumbá. Ou seja, se houver solicitação pelo grupo de

\footnotetext{
${ }^{6}$ Informação obtida na secretaria da ACERT, com base em seu estatuto, março de 2009.
} 
turistas de um tour pela cidade, a empresa providencia o que for necessário para sua realização.

\begin{tabular}{|c|c|c|c|c|c|}
\hline Empresas/Agências & $\begin{array}{l}\text { Escala de } \\
\text { atividades }\end{array}$ & Pesca & Ecológico & $\begin{array}{l}\text { City } \\
\text { tour }\end{array}$ & $\begin{array}{l}\text { Bolívia/ } \\
\text { Compras }\end{array}$ \\
\hline Empresa Canaã Turismo & Local & $x$ & $x$ & - & $x$ \\
\hline Empresa Raquel Tur. & Local & $x$ & - & - & $x$ \\
\hline $\begin{array}{l}\text { Empresa TCB Agências de } \\
\text { Viagens }\end{array}$ & Local & $x$ & - & $x$ & $x$ \\
\hline Empresa Sant' Tours & Local & $x$ & $x$ & - & $x$ \\
\hline Empresa Porto do Pantanal & Local & $x$ & - & - & $x$ \\
\hline $\begin{array}{l}\text { Empresa LMC Martins Pérola do } \\
\text { Pantanal }\end{array}$ & Local & $x$ & $x$ & - & $x$ \\
\hline Empresa Arara Pantaneira & Local & $x$ & - & - & $x$ \\
\hline Empresa Irmãos Marinho Ltda. & Local & $x$ & - & - & $x$ \\
\hline Empresa Camalote Tour & Local & $x$ & - & - & - \\
\hline Empresa Marques \& Esquivel Ltda. & Local & $x$ & $x$ & - & $x$ \\
\hline $\begin{array}{l}\text { Empresa HBS Agência de Viagens } \\
\text { e Turismo }\end{array}$ & Local & $\mathrm{x}$ & - & - & $x$ \\
\hline Empresa Piramiúna Pesca & Local & $x$ & $x$ & - & $x$ \\
\hline Empresa JDS Turismo & Local & $x$ & $x$ & - & $x$ \\
\hline Empresa Real Tour & Local & $x$ & - & - & $x$ \\
\hline Empresa O Pantaneiro & Local & $x$ & - & - & $x$ \\
\hline Empresa Pevê Tur & Local & $x$ & - & - & $x$ \\
\hline Empresa Pantanal Tours. & Local & $x$ & - & - & $x$ \\
\hline $\begin{array}{l}\text { Empresa Almirante Náutica e } \\
\text { Turismo }\end{array}$ & Local & $x$ & - & - & $x$ \\
\hline Empresa Mutum Turismo Ltda. & $\begin{array}{c}\text { Nacional, } \\
\text { Internacional, } \\
\text { Regional }\end{array}$ & $x$ & - & - & - \\
\hline Empresa Oliver Tur & $\begin{array}{c}\text { Nacional, } \\
\text { Internacional, } \\
\text { Regional }\end{array}$ & $x$ & $x$ & $x$ & $x$ \\
\hline $\begin{array}{l}\text { Agência de Viagens e Turismo } \\
\text { Pantur }\end{array}$ & $\begin{array}{c}\text { Nacional, } \\
\text { Internacional, } \\
\text { Regional }\end{array}$ & $x$ & $x$ & $x$ & $x$ \\
\hline
\end{tabular}

Figura 2 - Empresas de turismo cadastradas na ACERT, segundo a escala de atuação e o tipo de atividade, em março de 2009. Fonte: ACERT, 2009. (Organizado pelos autores). 
É marcante a importância do segmento da pesca na oferta do turismo corumbaense. Essa constatação aparece na infraestrutura de atendimento das agências locais que na sua maioria (90\%) possuem barco-hotel próprio estruturado para esse fim (Figura 3).

\begin{tabular}{|l|c|}
\hline \multicolumn{1}{|c|}{ Empresas/Agências } & Barco-hotel \\
\hline Empresa “O Pantaneiro" & Millenium \\
\hline Empresa Almirante Náutica e Turismo & Almirante \\
\hline Empresa Arara Pantaneira & Arara Pantaneira \\
\hline Empresa Camalote Tour & Flor de Camalote \\
\hline Empresa Canaã Turismo & Canaã \\
\hline Empresa HBS Agencia de Viagens e Turismo & Netuno \\
\hline Empresa Irmãos Marinho Ltda. & Veneza \\
\hline Empresa JDS Turismo & Paola \\
\hline Empresa LMC Martins Pérola do Pantanal & Kalypso \\
\hline Empresa Marques \& Esquivel Ltda. & Caiamã Vip \\
\hline Empresa Pantanal Tours. & Cabexy \\
\hline Empresa Pevê Tur & Pevê \\
\hline Empresa Piramiúna Pesca & Eré \\
\hline Empresa Porto do Pantanal & Peralta \\
\hline Empresa Raquel Tur & Indiaporã \\
\hline Empresa Real Tour & Real \\
\hline Empresa Sant'Tours & Celebridade \\
\hline Empresa TCB Agência de Viagens & Kasato Maru \\
\hline Empresa Triton & Marruá \\
\hline Empresa Mutum Turismo Ltda. & - \\
\hline Empresa Oliver Tur & - \\
\hline Agência de Viagens e Turismo Pantur & - \\
\hline
\end{tabular}

Figura 3 - Quadro das empresas de turismo cadastradas na ACERT, segundo propriedade de barco-hotel, em março de 2009. Fonte: ACERT, 2009. (Organizado pelos autores).

Isso não significa que a cidade só ofereça essa possibilidade, ao contrário, existem inúmeras outras possibilidades turísticas fortemente atreladas à cultura e à condição de fronteira. 
Em Ladário só existe uma agência de turismo, a Sonetur, que oferece passeios turísticos pela região do Pantanal e possui uma pousada no Porto da Manga, no rio Paraguai.

No distrito de Arroyo Concepción (Puerto Quijarro), existem apenas três agências de viagens e turismo que atuam no mercado somente com vendas de passagens terrestres (Andorinha, Cruceña) e aéreas (Aerosur, Gol, TAM Mercosur, TAM - Transporte Aéreo Militar). Duas delas (Vini Tours e Ecology Pantanal Travel) oferecem turismo ecológico, passeios e city tours na forma de indicação de empresas de Corumbá, sem, contudo estabelecer redes de cooperação ou alguma forma de parceria com as mesmas.

As empresas de turismo bolivianas dessa fronteira não trabalham com o turismo de pesca, apesar da localização no Pantanal boliviano com potencialidade para essa prática. A carência de barcos pesqueiros e barcoshotel foram as principais justificativas para o não oferecimento desse produto aos turistas. As empresas funcionam apenas como agências de viagem, vendendo passagens aéreas, rodoviárias e ferroviárias. Também não atendem outras modalidades de turismo, nem realizam city tour (Figura 4).

\begin{tabular}{|l|c|c|c|c|c|}
\hline \multicolumn{1}{|c|}{ Empresas/Agencias } & $\begin{array}{c}\text { Escala de } \\
\text { atividades }\end{array}$ & Pesca & Ecológico & City tour & $\begin{array}{c}\text { Venda de } \\
\text { passagem }\end{array}$ \\
\hline Hotel Bibozi & Nacional & - & - & - & $\mathrm{x}$ \\
\hline Ecology Pantanal Travel & Nacional & - & - & - & $\mathrm{x}$ \\
\hline Frontera Vini Tours & $\begin{array}{c}\text { Nacional e } \\
\text { internacional }\end{array}$ & - & - & - & $\mathrm{x}$ \\
\hline
\end{tabular}

Figura 4 - Quadro das empresas de turismo localizadas em Puerto Quijarro, segundo a escala de atuação e o tipo de atividade, em março de 2009.

Fonte: Informação oral, 2009. (Organizado pelos autores).

Contudo existe o interesse em trabalhar futuramente com as várias modalidades de turismo a fim de melhor aproveitar os potenciais existentes. Além disso, foi constatado um aspecto diferenciado e pouco comum quanto à 
oferta de infraestrutura e de possibilidades para a prática do turismo ecológico em Puerto Quijarro. A Base Naval da Marinha Boliviana, justificando a falta de opção de serviços e produtos oferecidos pela iniciativa privada, atendia a grupos de turistas, adaptando suas embarcações e até mesmo oferecendo serviços de restaurantes.

Em Puerto Suarez foram identificadas as agências TAM, Aerosur, Ferroviária Oriental e apenas uma empresa de turismo, a Bolivia Travel Tours que opera com emissão de passagens aéreas - explorando a existência do aeroporto local - e de passagens ferroviárias e rodoviárias, especialmente para Santa Cruz de La Sierra.

Em Corumbá não existe uma rede de cooperação formalizada das empresas de turismo e agências de viagens com os demais prestadores de serviços locais, bem como junto aos demais serviços concernentes às atividades turísticas desenvolvidas. O mesmo caso foi observado em Ladário e no lado boliviano. Informalmente ocorre a divulgação espontânea de ofertadores de serviços, mas isso não representa a configuração de uma rede e tampouco de acordos escritos ou verbais. São circunstanciais, ocasionais! $\mathrm{Na}$ opinião dos empresários de turismo de Corumbá, a principal dificuldade para se estabelecer uma rede de cooperação com o empresariado da Bolívia está na carência de infraestrutura do país vizinho, aliada à desarticulação política dos corumbaenses. Outro fator observado foi a concepção de que a formação de redes implicaria em custos que inviabilizaria economicamente sua proposição. A pesquisa não encontrou elementos que pudessem comprovar esse entendimento. Além disso, se pode perceber o receio dos empresários trabalharem com outro tipo de turismo que não seja o de pesca.

Puerto Suárez apresenta grande potencial para se transformar em um destino turístico pelas facilidades de acesso, que pode ser realizado tanto por via aérea, férrea ou terrestre. São oferecidos serviços aéreos com destino diversificado, que passam pela capital do departamento, em Santa Cruz de La Sierra, com vôos diários das empresas LAB (Lloyd Aereo Boliviano), TAM (Transporte Aéreo Militar) e Aerosur (Compañía Boliviana de Transporte Aéreo 
Privado), além de vôos internacionais, dentre os quais São Paulo (Brasil). O transporte por via férrea está conjugado à Puerto Quijarro, contando com 0 Terminal Ferrocarril operado pela empresa Oriental S.A. que oferece três tipos de serviços de veículos passageiros caracterizados como: Ferrobus, Rápido e Expresso del Oriente. A ligação rodoviária para o restante do país é realizada pela empresa Bus Expresso Transcarretón. $O$ transporte urbano para fins turísticos ocorre em táxis, que conta com uma frota de 40 veículos, pertencentes a três empresas de rádio táxis.

Puerto Quijarro fica estrategicamente localizado entre dois aeroportos com capacidade para operar vôos internacionais: de Puerto Suárez e de Corumbá. O transporte ferroviário ocorre da mesma forma que em Puerto Suárez, já que o terminal fica em Puerto Quijarro. Vale destacar que não existe ligação ferroviária de passageiros para o Brasil, mas apenas a linha em estado ocioso. O trem de passageiros opera no trecho boliviano, sob controle da Empresa Ferrocarril Oriental - EFCO S.A., com duas linhas principais:

a. a de Santa Cruz de la Sierra a Quijarro com 640 km de extensão, que se conecta com a brasileira Novoeste em Corumbá;

b. a de Santa Cruz de la Sierra a Yacuiba, com $539 \mathrm{~km}$ de extensão, de onde se conecta, através de Pocitos, com a malha ferroviária argentina, ligando-se à rede que serve as diversas regiões da Argentina e podendo atingir, através de Salta - Socompa, Antofagasta no Chile (FIEMT, 2000, p.14).

Portanto, a cidade representa grande potencial para atração de turistas para/através dessa fronteira. A ligação rodoviária internacional para o Brasil ocorre via duas empresas: a Viação Andorinha (brasileira) e a Cruceña (boliviana). Para o restante do país é efetivado pala empresa Bus Expresso Transcarretón. O transporte urbano é realizado em táxis, com 170 veículos divididos entre duas empresas de rádio táxis, três associações e duas cooperativas.

A cidade de Corumbá conta com aeroporto com capacidade para operar vôos internacionais, mas vem operando apenas com vôos diários para Campo Grande, realizado pela empresa TRIP (Transporte Aéreo Regional do Interior 
Paulista Ltda). A empresa Andorinha monopoliza o transporte rodoviário de passageiros ligando à capital do Estado. Apenas uma das dez saídas diárias passa por Ladário. $O$ transporte urbano é realizado por uma empresa de ônibus que liga os bairros mais afastados ao centro (Viação Canarinho). Essa mesma empresa realiza o transporte urbano intermunicipal que atende a cidade vizinha de Ladário e uma linha que vai até as proximidades da fronteira (cerca de 500 metros), no local onde é cobrado pedágio. A cidade conta com serviço de uma frota de 92 táxis, além de 217 de mototaxistas cadastrados. Ladário possui 43 taxistas e 80 mototaxistas cadastrados.

Em relação aos serviços de alimentação, Puerto Suárez oferece gastronomia que inclui pratos elaborados à base de pescado, comida típica oriental e carnes silvestres, com destaque para a de jacaré. Provavelmente em função da baixa demanda são poucos os restaurantes adequados para atendimento de turistas internacionais.

Em Puerto Quijarro a maioria dos restaurantes está concentrada ao longo da avenida principal e nas proximidades do terminal ferroviário. Esses são orientados para atender a demanda local. Entretanto, existem cinco restaurantes com capacidade para atendimento de turistas estrangeiros, em três pontos principais: proximidades da feirinha de Arroyo Concepción; na rodovia que dá acesso a Puerto Suarez e; no shopping de Puerto Aguirre. A cozinha local foi influenciada por imigrantes das terras altas (Cordilheira dos Andes), mas oferece iguarias com influência da culinária brasileira e de outras partes do mundo.

A cidade de Corumbá possui o serviço de alimentação mais complexo e diversificado dessa fronteira. Apresenta estabelecimentos que vão dos mais simples aos mais sofisticados, com gastronomia diversificada. Existem pratos elaborados com produtos da região que variam de carne, frango, peixes e frutos da terra, mas também por influência dos migrantes árabes, italianos e paraguaios, dentre outros. Ladário possui apenas um restaurante e churrascaria. 
Igualmente aos homens, as firmas mostram grande assimetria no espaço fronteiriço, sendo mais concentradas e diversas em Corumbá que nas demais localidades urbanas. Essa condição implica num maior peso nas relações de poder estabelecidas e no alcance de suas territorialidades.

\section{As instituições}

Para Santos (2008) as instituições são responsáveis pelas normas, ordens e legitimações do espaço tornado território. Todos os agentes têm sua importância no processo de produção do espaço. Contudo se percebe mais nitidamente a intencionalidade do Estado, por isso a opção pelo maior detalhamento do seu papel nesse contexto.

No lado brasileiro, o Estado participa através de projetos de desenvolvimento turístico no município de Corumbá, com parcerias nas três esferas de poder. Destaca-se, recentemente, a inclusão do município no projeto dos 65 Destinos Indutores do Turismo no país, além da finalização do projeto chamado "Trem do Pantanal" - especialmente destinado a turistas. Do lado boliviano existem investimentos em infraestrutura, principalmente a pavimentação asfáltica para atender os locais com atrativos turísticos. Outras instituições também desenvolvem atividades sazonais que atendem aos interesses turísticos, como o SEBRAE (Serviço Brasileiro de Apoio às Micro e Pequenas Empresas) e o SENAC, (Serviço Nacional de Aprendizagem Comercial). Além de algumas ONGs (Organizações Não Governamentais) como o IHP (Instituto Homem Pantaneiro), em Corumbá e a WWF (World Wide Fund For Nature), no lado boliviano.

A prefeitura de Corumbá, através da Fundação de Cultura e Turismo tem promovido ações para o fomento do turismo no município. O segmento de pesca (uma prática antiga) e o de eventos (que ganhou forte apoio governamental recentemente) são os únicos que podem ser considerados como consolidados. Em relação às demais modalidades, essa Fundação tem buscado parcerias com instituições federal, estadual e municipal para 
desenvolver projetos que venham criar e implementar novas alternativas para o município.

Um dos projetos que a Fundação de Cultura e Turismo tem participado junto com o Ministério do Turismo é o Estudo de Competitividade dos 65 Destinos Indutores do Desenvolvimento Turístico Regional. Já foram realizados vários seminários apontando como resultados o encaminhamento de propostas relacionadas à melhoria dos meios de transportes aéreo, ferroviário e aquaviário, capacidade de oferta de serviços e equipamentos turísticos, marketing, cooperação regional, monitoramento, fortalecimento da economia local, aspectos ambientais e a formação de um grupo gestor para o desenvolvimento do projeto (informação oral ${ }^{7}$ ).

Além do projeto de Condutores de Visitantes Mirins de Corumbá (mencionado anteriormente) também vem sendo desenvolvida pela Fundação de Cultura e Turismo, a sensibilização local para o turismo. A proposta ainda está sendo discutida internamente e visa divulgar as potencialidades turísticas do município, através de trabalhos realizados em escolas e estratégias de informação à população em geral.

Dentre as ações desenvolvidas pela Fundação de Cultura e Turismo, na direção do fortalecimento do segmento de eventos, destaca-se a elaboração do calendário anual que reflete nas condições de divulgação, gerando mais atração de turistas com reflexos positivos para a economia local. Esse calendário já está consolidado institucionalmente desde 2005, tendo anualmente o Carnaval, o Festival América do Sul, o Arraial do Banho de São João, a FEAPAN, o Festival Pantanal das Águas, o Festival Gastronômico e a Festa de lemanjá. Vale ressaltar que existem outros eventos que foram sendo inseridos nesse contexto, como é o caso da Noite da Seresta, que ocorre uma vez por mês e da quermesse da APAE (Associação de Pais e Amigos dos Excepcionais), no dia 7 de setembro - ambos realizados na Praça da Independência.

\footnotetext{
${ }^{7}$ As informações sobre as ações destinadas ao fortalecimento do turismo da Prefeitura Municipal de Corumbá foram obtidas durante entrevista com o Secretário de Turismo local, em março de 2009.
} 
O Carnaval é promovido pela Prefeitura Municipal, sendo o mais antigo e animado do Estado ${ }^{8}$. Conta com apresentação de escolas de samba ( $1^{\circ}$ e $2^{\circ}$ grupo), blocos e cordões que passam pela principal rua da cidade, a Frei Mariano, desembocando na Avenida General Rondon. O Festival América do Sul acontece, geralmente no segundo trimestre, sendo produzido pela Secretaria de Cultura do governo estadual, que busca consolidar a integração dos países da América do Sul através de apresentações artísticas, palestras, exposições de artesanatos, seminários, filmes, dando ênfase à cultura e ao turismo. O Arraial do Banho de São João ocorre no mês de junho, cujas procissões percorrem trechos da cidade com bandas e andores numa mistura de festa e fé religiosa até as margens do rio Paraguai, para o banho do santo. A Feira Agropecuária do Pantanal (FEAPAN) acontece juntamente com as festividades de aniversário da cidade, no mês de setembro, promovida pela Prefeitura e Sindicato Rural de Corumbá. Já o Festival Pantanal das Águas é um evento que ocorre no final de outubro e início de novembro, marcando o final do período liberado para pesca, sendo realizado numa parceria entre Prefeitura e TV Globo. Engloba o Festival Internacional de Pesca do Pantanal, o Campeonato de Pesca Infantil, a travessia a nado do rio Paraguai, o Festival de Samba e a Mostra de Teatro. Entre o final do mês de novembro e início de dezembro ocorre o Festival Gastronômico que divulga a diversidade cultural através da culinária local com pratos elaborados com produtos da região, sendo promovido pela Prefeitura de Corumbá. As festividades anuais são encerradas com a Festa de lemanjá, articulada também pela Prefeitura de Corumbá, que ocorre junto às comemorações de final de ano.

Em Ladário não existe um calendário turístico, apenas as festividades tradicionais que possuem potencial de ser exploradas para o turismo. As principais festas são: o carnaval; a emancipação do município comemorada em março; a semana santa, com procissões, quermesses e missas campais; as festas juninas tradicionais, ocorrendo no mesmo mês a comemoração cívicomilitar da vitória na batalha naval Riachuelo; em setembro acontecem as festas

\footnotetext{
${ }^{8}$ Segundo informações da Fundação de Cultura e Turismo/Corumbá, reúne cerca de 20 a 30 mil turistas, além da população local, nos dias de carnaval.
} 
comemorativas da Semana da Pátria e o aniversário da cidade (ambas com desfile cívico-militar), além da Festa do Peixe, no primeiro domingo do mês, com apresentações musicais, barracas com os mais diversos pratos de peixe, sempre no porto geral de Ladário, às margens do rio Paraguai; a Festa da Padroeira da Cidade (Nossa Senhora dos Remédios) ocorre no mês de outubro ao lado da igreja de mesmo nome, com procissão, quermesses, shows musicais e; por fim, em dezembro se comemora o dia do Marinheiro (aniversário do Almirante Tamandaré), festejado na Avenida 14 de março, local da maioria dos eventos cívico-militares.

Em Puerto Quijarro, o calendário de eventos está baseado em suas manifestações culturais. Em fevereiro acontece o carnaval com a duração de três dias, apresentando desfiles e escolha da rainha do carnaval. Diferentemente do Brasil, as festividade do carnaval não acontecem nas ruas ou nos clubes e sim nas casas dos festeiros. Em março os bolivianos comemoram o dia do mar, com desfiles cívicos e militares, nos quais reivindicam uma saída soberana ao Pacifico. Também é comemorado, em 19 de março, o dia dos pais e da mulher. Em abril é festejado o dia da criança com a distribuição de alimentos e roupas para crianças carentes. Em 27 de maio é comemorado o dia das mães. Em 13 de junho acontece a festa da cidade com duração de 08 dias e várias atividades como palestras em escolas, comemorações cívicas e militares, além das manifestações culturais (dança, música e gastronomia local) e no dia 24, a festa de São João. Em 06 de agosto é comemorada a independência da Bolívia com celebrações cívicas e militares e quermesse com apresentações culturais. Em setembro acontece a feira do pescado e se comemora o dia do estudante, dos namorados e início da primavera, além do aniversário de Santa Cruz de La Sierra (dia 24). Em outubro, no segundo domingo, se comemora a tradição cruceña, com manifestações culturais advindas de todos os departamentos bolivianos, promovendo uma integração entre os povos através das tradições culturais de cada cidade. Em dezembro existe a festa do dia 08, em comemoração à Nossa Senhora de Cotoca, padroeira do departamento de Santa Cruz. Também ocorre a campanha natalina, que é a mobilização da população para 
arrecadação de brinquedos que são entregues no dia 14 de dezembro com a realização de uma grande festa e participação da população em shows, danças, etc.

Em Puerto Suárez as festividades são, praticamente, as mesmas de Puerto Quijarro. A exceção fica por conta da festa comemorativa da fundação da cidade que ocorre no dia 10 de novembro. A partir de 2006 o governo municipal, através da Comisión de Desarrollo Económico Local y la Cámara de Industria y Comercio (CAINCO) passou a organizar, anualmente a Expopantanal. Essa exposição mostra produtos agrícolas e tecnológicos de diferentes países, envolvendo diversos setores: agricultura, artesanato, indústria e siderurgia, turismo e comércio. Vale destacar que não existe um calendário de eventos voltados para o turismo, mas essas manifestações apresentam potencial para o desenvolvimento da atividade.

Neste sentido se percebe a diferença entre os calendários de Corumbá, das demais cidades dessa fronteira. Os eventos que acontecem em Corumbá são um misto de cultural-institucional, com a finalidade de divulgar a cultura, bem como promover e implementar o turismo no município. As festas já foram apropriadas pelos agentes produtores do turismo. Em Puerto Quijarro, Puerto Suárez e Ladário, os eventos são produtos das manifestações culturais, apresentando somente potencialidades de ser apropriada pelo turismo.

Nos municípios bolivianos não existem conselhos de turismo. Corumbá e Ladário tiveram iniciativas em torno dessa conformação no ano 2001, mas deixou rapidamente de apresentar funcionalidade. Em 2005 passou a funcionar o Fórum de Turismo da Região do Pantanal, contemplando municípios e instituições brasileiras. Fazem parte dele: as entidades ligadas ao turismo das prefeituras de Corumbá, Ladário, Miranda, Aquidauana e Anastácio, além da Associação Brasileira de Agências de Viagens do Mato Grosso do Sul (ABAV/MS), Grupo de Operadoras de Turismo do Estado de Mato Grosso do Sul (GOPAN/MS), ECOA - Ecologia e Ação, Rede Pantanal, Fundação de Turismo de Mato Grosso do Sul, SEBRAE e UFMS - Campus de Aquidauana. 
Dentre as outras instituições que apóiam ao turismo, o SEBRAE tem contribuído para seu fortalecimento através de ações pontuais. Apóia os empresários através de programas e estruturação de projetos, orientando e capacitando empreendimentos turísticos. Para essa finalidade são oferecidos cursos, treinamentos, palestras, consultorias, fóruns, oficinas, seminários e workshops. O Trem do Pantanal, que é um projeto já consolidado na fase preliminar (ligando Campo Grande a Miranda) e que chegará até a cidade de Corumbá, além da travessia do Pantanal que ligará Mato Grosso do Sul e Mato Grosso, em fase de construção, contam com apoio e participação do SEBRAE na qualificação da mão-de-obra.

O SENAC atua apoiando na formação de profissionais em turismo na área de hotelaria, gastronomia e guias, oferecendo cursos técnicos para guias de turismo, cursos para recepcionistas, camareiras, copeiros e garçons.

O Instituto Homem Pantaneiro (IHP) cria uma série de alternativas que são apropriadas pelos agentes produtores do turismo, como o resgate da cultura do homem pantaneiro, mantendo viva a tradição de um povo e de uma região situada na fronteira oeste do Brasil. Através do Moinho Cultural ensina, desde música regional acompanhada nas tradicionais violas de cocho, até música erudita, balé clássico e outras modalidades de danças. Seus espetáculos são apresentados tanto na sede quanto na Praça Generoso Ponce, atraindo um público numeroso (frequentemente superando mil espectadores).

Em Ladário o turismo não recebe a mesma organização. Em 2001 foi criada a Fundação do Turismo e Meio Ambiente, mas somente em 2009 é que se começou a catalogar os pontos turísticos e participar de congressos para divulgação.

No município de Puerto Quijarro foi elaborado, pela WWF, um plano de turismo que vislumbra ações de 2008 a 2013, denominado de Estrategia de Desarrollo Turístico. Seu principal objetivo é melhorar a qualidade de vida dos habitantes locais através da exploração do turismo, sendo dividido em três programas. $O$ primeiro aponta para a necessidade de fortalecer e capacitar as 
instituições públicas e privadas na temática do turismo no município e criação de um comitê gestor e de associações de operadoras de serviços. O segundo objetiva promover a imagem do Pantanal boliviano na jurisdição municipal através de políticas públicas de fomento, sensibilização da população, criação do conceito de cultura quijarreña, organização de feiras e eventos e estabelecimento de um produto "Pantanal boliviano". O terceiro visa dotar de infraestrutura e equipamentos públicos para apoiar a atividade do turismo, incluindo a construção de um Muelle ${ }^{9}$ - Mirador Turístico, da Avenida Costanera ligando Puerto Quijarro-Puerto Suárez, um Centro de Interpretação Turística e Artística, um Parque Ecológico, um Mercado Municipal Turístico Plaza Arroyo Concepción, diversos centros de Informações Turísticas, embarcações menores e um centro de capacitação artesanal.

Não existe uma secretaria especificamente de turismo. As ações ligadas a essa temática são conduzidas por um conselheiro municipa ${ }^{10}$ responsável pela Unidade de Meio Ambiente e Recursos Naturais. Suas atribuições estão ligadas à proposição de projetos que envolvem a conservação da natureza, o cuidado para evitar a poluição dos rios, conservação nacional de área protegida, reciclagem do lixo, desenvolvidos com alunos de escolas públicas e a comunidade em bairros da cidade. Logo, se pode notar que as ações sobre turismo no município não encontram relevância em termos de organização administrativa.

O instrumento de planejamento do município de Puerto Suárez é o Plano de Desenvolvimento Municipal (PDM), construído com apoio do WWF no ano 2000, considerando um horizonte de cinco anos. Nele, o turismo foi considerado como uma atividade econômica promissora para o município, porém reconhecendo gargalos a serem superados como o da necessidade de formação de recursos humanos, melhoria da infraestrutura turística e da condição das estradas locais. Apesar desse reconhecimento, o planejamento para os primeiros cinco anos incluíram a construção de um cais de turismo (muelle turístico) e a implementação de um programa de ecoturismo e de

\footnotetext{
${ }^{9}$ Espécie de passarela sobre as águas.

${ }^{10}$ Equivalente a vereador, no Brasil.
} 
turismo cultural no município. Além disso, incluía estratégias de promoção, capacitação e gestão do turismo, no contexto do Programa de Desenvolvimento Econômico que ainda não foram executados.

Um dos objetivos focados no turismo desse programa era tornar o município produtivo, desenvolvendo o potencial do setor de ecoturismo e investindo no setor público e privado, visando garantir a sustentabilidade dos recursos nas zonas urbana e rural. Era almejado promover o desenvolvimento de um turismo de qualidade, sustentável, capaz de aumentar a arrecadação e melhorar a distribuição dos lucros gerados pelo turismo, através da descentralização da oferta para diversas áreas. A estratégia de capacitação sinalizava para o pessoal das associações e empresas prestadoras de serviços aos turistas, na interpretação da natureza e do comportamento dos turistas, especialmente em áreas protegidas, treinamento para funcionários de hotéis, restaurantes e transportes com foco na qualidade dos serviços.

A estratégia de promoção centrava na conscientização sobre o turismo, aumentando o fluxo de visitantes ao município. Em relação à gestão do turismo se buscava fortalecer as organizações e instituições locais de turismo e equipar os funcionários municipais para administração eficiente das operações de turismo. Outro aspecto importante era o da sensibilização da população em geral sobre a importância do turismo como atividade econômica para o município, da seriedade em oferecer um serviço de qualidade com um bom atendimento aos visitantes. Todas essas perspectivas não foram levadas adiante, colocando em dúvida a capacidade do plano em atender as necessidades locais e/ou a capacidade de articulação política para realização do mesmo.

A prefeitura de Puerto Suárez não conta com uma secretaria de turismo, nem com pessoal técnico que se responsabilize pela atividade no município, essa responsabilidade fica a cargo de um assessor, nos mesmos moldes de Puerto Quijarro. Ou seja, o equivalente a um vereador nos municípios brasileiros é quem cuida politicamente dessa temática. 
Tais condições demonstram a grande diferença de apropriação do potencial turístico pelas instituições de maneira compartilhada com as firmas. Enquanto Corumbá possui um grau de organização mais avançado, os demais municípios ainda vivenciam o principiar organizativo da atividade turística.

\section{O meio ecológico}

Milton Santos (2008) tratou o meio ecológico como um conjunto de complexos territoriais que oferece sustentação para a realização do trabalho humano. Esses complexos são dinâmicos e se relacionam diretamente com os demais componentes do espaço, influenciando e sendo influenciado. Nesse entendimento, se trata do meio físico que comporta os atrativos apropriados culturalmente a serem explorados pela atividade turística (nesse caso particular) ou com potencial de sê-lo.

Essa fronteira tem a peculiaridade de assentar-se, geomorfologicamente, numa área entre a morraria (cerros) e o rio Paraguai e seu complexo de drenagem. Configura-se como um complexo de áreas planas e morros em contato direto com a planície do Pantanal. Nos espaços urbanos, no escopo dessas feições, estão: o morro do Cruzeiro (ou de São Felipe), o Eco Parque Cacimba da Saúde, o Parque Natural Municipal Marina Gatass, o Porto Tamarinero, o Centro Ecológico El Tumbador, a Baía de Cáceres, dentre outros.

As cidades estão localizadas em ambientes empiricamente muito semelhantes, relativamente planos, mas ainda não existem estudos mais específicos e comparativos sobre sua formação geológica e geomorfológica. É possível deduzir, de acordo com Monteiro (1997, p. 71) que é formada por solos "[...] litólicos com uma camada superficial de argila e logo abaixo rochas calcárias, são, portanto, solos rasos, com pouca profundidade oriundos da decomposição de rochas". Pode-se deduzir que são solos com baixa taxa de porosidade que podem acarretar, em condições de intensa pluviosidade, problemas com a drenagem e consequente alagamento. 
O clima é do tipo tropical com chuvas concentradas no verão e inverno registrando os menores índices pluviométricos. O clima local é influenciado pela forte continentalidade (distância dos oceanos), tornando-o mais seco, mas, sendo amenizado pela umidade advinda do complexo de drenagem da bacia do rio Paraguai no Pantanal. Como não se percebe, empiricamente, grandes diferenças climáticas nesta fronteira, é possível se apropriar da explicação de Zavatini (1992, p. 83) para Corumbá quando aponta que:

[...] a média das precipitações anuais fica ao redor dos 1.100 $\mathrm{mm}$., os totais de primavera-verão se equilibram e ultrapassam 880 00, evidenciando um outono-inveno seco (250 mm.). Os dados registrados nesta cidade indicam uma umidade do ar bastante elevada e grande freqüência de calmarias. Apontam, também, máximas de verão muitas vezes superiores a $35^{\circ} \mathrm{C}$, contrastando com as mínimas de inverno que beiram $0^{\circ} \mathrm{C}$, revelando a continentalidade de seu clima. [...].

O fato de o espaço fronteiriço estar localizado na faixa dos $19^{\circ}$ de latitude sul é motivo de freqüentes passagens da Frente Polar Atlântica, associada a pouco expressiva presença de barreiras naturais à Massa Polar Atlântica. Além disso, Zavatini (1992) acrescenta que se trata de uma área controlada pela Massa Tropical Continental que recebe influência, ainda que pouco significativa, da Massa Equatorial Continental (primavera-verão) e Massa Tropical Atlântica (outono-inverno).

Em relação às temperaturas, essa região apresenta elevada amplitude térmica quando analisadas suas médias. Valverde (1972) encontrou, para Corumbá, a média da máxima temperatura verificada no mês de dezembro, em $33,8^{\circ} \mathrm{C}$ e a média da mínima registrada no mês de julho em $16,2^{\circ} \mathrm{C}$, representando uma diferença de $17,6^{\circ} \mathrm{C}$. Contudo, Monteiro (1997) aponta que na cidade de Corumbá já foram registrados valores de até $40^{\circ} \mathrm{C}$, em qualquer mês do ano. Os valores térmicos mais extremos ocorrem em novembro, quando já foram registrados $41,8^{\circ} \mathrm{C}$. Essa condição produz algo que Tarifa (1984, p. 13) chamou de "[...] um grande stress climático para a flora, a fauna e os próprios seres humanos, cujos organismos se encontram adaptados a um regime climático com grande excedente de calor". 
Apesar das elevadas temperaturas registradas essa região de fronteira apresenta elevada taxa média de umidade relativa do ar. Monteiro (1997) aponta uma média anual de $73,1 \%$, sendo que nos meses de verão ultrapassam os $80 \%$ de umidade relativa do ar. Valverde (1972), Tarifa (1984) e Monteiro (1997) são unânimes em apontar as duas estações bem definidas: a) primavera-verão, quando chove em torno de $80 \%$ do total pluviométrico regional e; b) outono-inverno, marcada por ser uma estação com baixo volume pluviométrico. Entretanto, essa é a região que menos chove no estado de Mato Grosso do Sul, alcançando média anual inferior a $1.100 \mathrm{~mm}$, enquanto nas demais regiões os índices superam sempre os 1.200 mm./anuais.

De acordo com Monteiro (1997) predominam ventos de leste, sendo mais fortes no período mais seco, correspondente às estações primaverainverno. De maneira geral são ventos moderados, sendo incomuns rajadas superiores a $50 \mathrm{~km} / \mathrm{hora}$.

Foi possível perceber que o meio ecológico apresenta algumas dificuldades para a ocupação humana quanto ao tratamento de esgoto e construção de galerias pluviais. A presença de rocha calcária muito próxima da superfície dificulta a perfuração para abertura das valas a fim de dar passagem às tubulações. Contudo, a utilização de explosivos e, atualmente de maquinários mais modernos têm conseguido perfurar esse tipo de rocha, se bem que com significativas dificuldades. Essa tem sido uma das razões para a região apresentar sérios problemas quanto ao saneamento ambiental. Somente Corumbá, muito recentemente (2007-2010, com as obras do $\mathrm{PAC}^{11}$ ) avançou significativamente na construção de rede de esgoto.

Por outro lado, a menor presença de chuva, os ventos fracos, a umidade relativa do ar, as feições geomorfológicas proporcionam boas condições de aproveitamento para o turismo. Essas condições são confrontadas com as elevadas temperaturas que exigem maiores investimentos em equipamentos, como condicionador de ar, por exemplo, a fim de minimizar seus efeitos. Logo,

\footnotetext{
${ }^{11}$ PAC - Programa de Aceleração do Crescimento. Foi lançado pelo governo Lula em janeiro de 2007, visando estimular o crescimento da economia brasileira, através do investimento em infraestrutura (portos, rodovias, aeroportos, redes de esgoto, geração de energia, hidrovias, ferrovias, etc.).
} 
é possível vislumbrar um complexo sistema de relacionamentos entre os componentes do espaço materializando distintas formas.

\section{As infraestruturas}

A atividade turística tem a capacidade de dinamizar outros segmentos econômicos na vida da cidade. Além dos hotéis, barcos-hotel, agências, sistema de transporte intermunicipal (ônibus, locação de vans, táxis, outros veículos menores), interestadual, dentre outros, existe o transbordamento natural das receitas com o turismo para a rede de restaurantes, supermercados, bares, lanchonetes, padarias, açougues, postos de combustíveis. Ocoorre uma distribuição da renda para múltiplas atividades, contratação de trabalhadores permanentes e temporários (principalmente durante os eventos).

Algumas prefeituras já perceberam que atrair turistas passou a ser um ótimo investimento. Dessa forma, são recriados espaços para atender a demanda turística, ao mesmo tempo em que outros espaços são requalificados e valorizados em conformidade com suas peculiaridades. Tal condição implica a (re)criação de infraestruturas.

Santos (2008, p. 17) entende que "As infraestruturas são o trabalho humano materializado e geografizado na forma de casas, plantações, caminhos etc." Vale ressaltar, como afirmado anteriormente com base nesse mesmo autor, que os elementos do espaço são intercambiáveis e plenamente relacionáveis. No caso das infraestruturas esse argumento se torna ainda mais perceptível. Elas são resultantes das ações e vontades de outros elementos como os homens, as firmas e as instituições. Além disso, decorrem de investimentos tecnológicos num meio ecológico. Portanto, se relaciona plenamente com todos os demais elementos.

Cabe lembrar que esta fronteira apresenta dois aeroportos internacionais, sendo um em Corumbá e outro em Puerto Suarez. Conforme Allgoewer (2005, p.22-3), o 


\begin{abstract}
“[...] aeropuerto Tnte. de Aviación Salvador Ogaya Gutiérrez tiene una pista pavimentada de 2000 metros, sin iluminación nocturna [...] Por tratarse de un aeropuerto de frontera, funciona también el control migratorio y aduanero". O Aeroporto Internacional de Corumbá possui uma pista de asfalto que mede 1.500 metros tendo sido inaugurado em 1960 e em 1975 passou para controle da Infraero (Empresa Brasileira de Infraestrutura Aeroportuária).
\end{abstract}

Moura (2008) ao estudar a Gruta do Lago Azul em Bonito-MS, com o mesmo referencial aqui utilizado, indicou as materializações implantadas para favorecer o aproveitamento turístico. Optou-se por tratar, neste trabalho, somente as infraestruturas especialmente construídas para implementar ou dinamizar o turismo. Evidentemente a construção de uma ponte sobre um rio, a ampliação da capacidade de oferta de energia, de telefonia e de portas para internet banda larga, por exemplo, ajudam a melhorar a qualidade dos serviços ofertados ao turismo. Mas esses não foram objetos dessa análise que priorizou os investimentos motivados para apropriação do espaço pelos agentes do turismo. Chamamos esses investimentos de novas configurações geográficas pelo fato de terem sido recentemente (re)inventadas com finalidade turística.

Essas territorializações emanadas dos governos municipais são observadas muito significativamente na cidade de Corumbá, seguido de Puerto Quijarro. Menos significativas, mas ainda relevantes foram as intervenções do governo municipal de Puerto Suarez. Por outro lado, não foi encontrado nenhum arranjo espacial motivado pelo turismo na cidade de Ladário.

Em Corumbá, a prefeitura municipal passou a olhar com mais atenção para o turismo a partir do ano de $2004 \mathrm{com}$ a mudança da gestão municipal que criou uma Secretaria específica para o turismo. Isso não significa negar a existência anterior de um setor para atender essas atividades, mas que a partir de então se passou a ter o turismo como uma potencialidade a ser explorada como geradora e distribuidora de renda. Nas gestões anteriores o turismo era tratado junto a uma secretaria que integrava os assuntos de meio ambiente e cultura, portanto sem preocupações específicas. 
Uma das transformações que pode ser destacada foi a revitalização do Porto Geral de Corumbá - um conjunto de construções históricas que atualmente se configura como um dos principais pontos turísticos da cidade. Em meados do século XIX, foi $\circ 3^{\circ}$ maior porto da América Latina onde desembarcavam transatlânticos vindos da Europa e da Argentina com mercadorias para venda, além da compra de produtos locais. Abrigava grandes empórios, bancos internacionais, curtumes e a primeira fábrica de gelo do Brasil (SILVA, 2006).

Corrêa; Corrêa; Alves (1985, p.81) afirmam que "Somente em 1985 que estudiosos observaram e preocuparam-se com os efeitos do progressivo abandono da área mediante a transformação de alguns prédios em cortiços e a descaracterização arquitetônica de muitos outros". Em função de sua relevância histórica para a população corumbaense, para ○ Brasil e para humanidade, o Casario do Porto foi tombado em 1992. Segundo Silva (2006), a partir do ano de 2002, com recursos do Programa Monumenta ${ }^{12}$ e da iniciativa do Governo (nas suas várias esferas, especialmente da municipal), dos representantes da iniciativa privada (que participaram direta ou indiretamente) e das entidades da sociedade civil organizada, o casario começou a ser restaurado.

Dentre as várias transformações do uso dos espaços do Porto Geral de Corumbá para sua apropriação pela atividade turística, Silva (2006) destacou especialmente três, que foram tombados e cuja revitalização estava atrelada à composição de atrativos turísticos: o Armazém da extinta Empresa de Portos do Brasil - Portobrás, a Casa Vasquez \& Filhos e o Edifício Wanderley, Baís \& Cia. A partir dessas informações organizamos um quadro (Figura 5) com a finalidade de destacar essas mudanças na forma de uso e da sua apropriação pelo turismo.

\footnotetext{
${ }^{12}$ O Programa Monumenta é realizado pelo Ministério da Cultura, e pelo Instituto do Patrimônio Histórico e Artístico Nacional (IPHAN), em parceria com a UNESCO. O Programa é executado com recursos de empréstimo do Banco Interamericano de Desenvolvimento (BID), da União, Estado e Municípios. Sua finalidade é revitalizar, de maneira sustentada, os principais conjuntos patrimoniais urbanos do país. (SILVA, 2006).
} 


\begin{tabular}{|l|l|l|}
\hline \multicolumn{1}{|c|}{ Prédio construído } & \multicolumn{1}{|c|}{ Novo arranjo } & \multicolumn{1}{c|}{ Turismo desejado } \\
\hline Armazém da Portobrás & Centro de Convenções & $\begin{array}{l}\text { Turismo de Negócios e de } \\
\text { Eventos }\end{array}$ \\
\hline Casa Vasquez \& Filhos & $\begin{array}{l}\text { Memorial do Homem } \\
\text { Pantaneiro }\end{array}$ & Turismo Cultural \\
\hline $\begin{array}{l}\text { Edifício Wanderley, Baís \& } \\
\text { Cia }\end{array}$ & $\begin{array}{l}\text { Museu da História do } \\
\text { Pantanal (Muhpan) }\end{array}$ & Turismo Cultural \\
\hline
\end{tabular}

Figura 5. Quadro da transformação de uso dos espaços e apropriação turistica do Porto Geral de Corumbá-MS.

Fonte: Adaptado pelos autores a partir das informações de Silva (2006).

Constatou-se, nessa perspectiva, que a cidade de Corumbá tem passado por várias modificações em termos de infraestrutura básica, como pavimentação asfáltica e saneamento, além da melhoria e revitalização de alguns potenciais turísticos urbanos (Porto Geral, praças, prédios históricos). Também são vislumbrados esforços de incremento da malha ferroviária destinada ao aproveitamento turístico, como é o caso do Trem do Pantanal, em fase de implantação e que se destina exclusivamente a esse fim.

Em Puerto Quijarro, atualmente o turismo consolidado é o de compras, que há algumas décadas atrai especialmente brasileiros pelo diferencial de preço e pela diversidade de oferta. Em conversa informal com os moradores locais foi possível apurar que a localidade ainda não está preparada para trabalhar outros segmentos turísticos devido à carência de infraestrutura para atendimento dos visitantes. Contudo, os arredores da feira em Arroyo Concepción estão sendo pavimentados desde o final de 2008 com recursos da prefeitura municipal, especialmente advindos do pedágio que começou a ser cobrado no ano de 2006 com a finalidade de investimentos em obras públicas.

Na cidade de Puerto Suarez, na Bolívia, a baía de Cáceres começou a passar por transformações motivadas pela procura do lugar para o turismo de contemplação. Na década de 1990 foi construído um muelle para facilitar o 
embarque/desembarque em pequenas embarcações de pescadores e em 2009 uma praça, imediatamente ao lado da baía, ganhou um visual novo, arranjos florísticos e estrutura para abrigar variados eventos.

Diante das territorializações construídas pelos gestores públicos e apropriadas pelo turismo, se percebeu que é bastante diferente a forma do arranjo entre os elementos do espaço turístico fronteiriço. Tal arranjo está fundado no tempo histórico de cada lugar, nas articulações do tempo presente, nos interesses e na capacidade de articulação política dos atores territoriais.

\section{Considerações finais}

Essa fronteira produz um emaranhado de relações, de fluxos. Os seus elementos espaciais imbricam complexas racionalidades ora aproximando, ora afastando e outras vezes desconsiderando as possibilidades que a fronteira pode traduzir. Existe uma enorme assimetria entre os elementos do espaço dessa fronteira, tendo Corumbá como território mais privilegiado do ponto de vista das ações dos homens, das firmas, das instituições e das infraestruturas. O meio ecológico é comum nesse espaço, porém sua apropriação é diversa, tendo um melhor aproveitamento para a atividade turística pelos atores/agentes produtores do espaço corumbaenses.

Existe um enorme potencial a ser explorado, mas carece de um planejamento integrado e criação de redes de cooperação socioeconômicas. Implica lidar com a fronteira: um espaço apropriado por quatro territórios na escala municipal e dois na escala nacional. Essas características, aliadas da assimetria demonstrada entre os elementos do espaço precisam ser consideradas no ato de planejar qualquer parte desse espaço fronteiriço. 


\section{Referências}

ALLGOEWER, Karin. Estrategia de turismo para el municipio de Puerto Suárez. Puerto Suárez: sn, 2005. (Documento elaborado para o World Wildlife Fund WWF).

CORRÊA, Valmir Batista; CORRÊA, Lúcia Salsa; ALVES, Gilberto Luiz. Casario do porto de Corumbá. Campo Grande: Fundação de Cultura de Mato Grosso do Sul, 1985.

FIEMT. Federação das Indústrias no Estado de Mato Grosso. Projeto logística de transportes no centro oeste sul-americano. Cuiabá-MT: FIEMT, 2000.

MONTEIRO, Maria José. Efeitos ambientais da urbanização de Corumbá - MS. Brasília: Instituto Brasileiro do Meio Ambiente e dos Recursos Naturais Renováveis, 1997.

MOURA, Flávia Neri de. Entre estalictites e estalagmites: territorialidades no monumento natural da gruta do Lago Azul, Bonito-MS. Aquidauana, MS: UFMS/CEUA, 2008, 123 f. (Mestrado em Geografia).

OLIVEIRA, Tito Carlos Machado de. Uma fronteira para o pôr-do-sol. Campo Grande: Editora UFMS, 1998.

SANTOS, Milton. Espaço e método. 5.ed. São Paulo: Edusp, 2008.

SANTOS JÚNIOR, Athayde Oliveira dos. O espaço turístico da fronteira do Brasil (Corumbá-MS) com a Bolívia. Corumbá, MS: UFMS/PPGEF, 2010, 111 f. (Dissertação de Mestrado em Estudos Fronteiriços).

SILVA, Andreza Regina Moreira da. Porto Geral de Corumbá: Alternativa para o fortalecimento da criação de um novo produto Turístico? Corumbá: Universidade Católica Dom Bosco/Instituto de Ensino Superior do Pantanal, 2006, 95 f. (Monografia de graduação em Turismo).

SILVA, Giane Aparecida Moura da. O trabalho infantil na região de fronteira Brasil-Bolívia. Corumbá, MS: UFMS/PPGEF, 2009. 123 p. (Dissertação de Mestrado em Estudos Fronteiriços).

TARIFA, José Roberto. O sistema climático do Pantanal: da compreensão do sistema à definição de prioridades de pesquisa climatológica. In: Anais de $1 \underline{0}$ Simpósio sobre Recursos Naturais e Sócio Econômicos do Pantanal. Corumbá - MS: EMBRAPA, 28 de novembro a 4 de dezembro de 1984.

VALVERDE, Orlando. Fundamentos geográficos do planejamento do município de Corumbá-MS. Revista Brasileira de Geografia, ano 34, n.1, jan/mar. Rio de Janeiro: IBGE, 1972, p. 49-144.

ZAVATINI, João Afonso. Dinâmica climática no Mato Grosso do Sul. Geografia, Rio Claro, v. 17, n. 2, p. 65-91, out. 1992. 